\title{
A globalizaÇão doS direitos humanos FUndamentais NA CONTEMPORANEIDADE: IMPACTOS DA INTERNACIONALIZAÇÃO DO DIREITO
}

The effectiveness of international treaties and conventions on fundamental rights in the globalized society: impacts in contemporary

\section{Lucélia Aparecida de Sousa Lima}

Mestranda bolsista CAPES/PROSUP pelo Programa de Mestrado em Direito do Centro Universitário de Osasco-UNIFIEO. Bacharel em direito pela Universidade Cidade de São Paulo. Advogada. Pós-graduada em direito constitucional com ênfase em direitos humanos e em docência no ensino superior pela Universidade Nove de Julho. E-mail: lucelialima@adv.oabsp.org.br.

RECEBIDO EM: 25.10.2013

Aprovado EM: 25.01.2013

"O Direito Internacional dos Direitos Humanos pressupõe como legítima e necessária a preocupação dos atores estatais e não estatais a respeito do modo pelo qual os habitantes de outros Estados são tratados.

(Kathryn Sikkink)

"A essência dos Direitos Humanos é o direito a ter direitos."

(Hannah Arendt)

\section{Resumo}

Este artigo tem como objetivo investigar a efetividade da internacionalização dos direitos humanos, em mundo globalizado, estes direitos já existiam, embora nem sempre fossem considerados, em razão dos óbices no que concerne a relativização da soberania de cada Estado, no entanto, na contemporaneidade a concretização dos direitos inerentes ao homem que tem ganhado forças paulatinamente, muitas vezes provocando modificações nas Constituições em razão do receio de represálias dos Tribunais e Organizações Internacionais, tendo como escopo as mudanças que internacionalização dos direitos humanos na América Latina, Argentina principalmente na Constituição Brasileira. 
Há uma preocupação Internacional que impacta países membros de Convenções e Tratados que versem a respeito dos direitos humanos, com o escopo de a precaução de represálias no âmbito Internacional no tocante a violação dos direitos humanos em um mundo globalizado na contemporaneidade. Atualmente o reconhecimento e a proteção dos direitos fundamentais do homem têm transformado as Constituições modernas democráticas com base na internacionalização dos direitos humanos.

Palavras-chave: Globalização. Direitos humanos. Efetividade. InternacionalizaÇão. Constituições. Soberania nacional. Modificações. Tribunais Internacionais.

\section{Abstract}

This article aims to investigate the effectiveness of the internationalization of human rights in a globalized world, these rights existed, although not always considered due to the obstacles, co concerning the relativization of the sovereignty of each state, however, is the contemporary embodiment rights inherent to man that has gained strength gradually, often causing changes in the constitutions because of fear of reprisals from the Courts and International Organizations, having as scope changes that internationalization of human rights in Latin America, Argentina especially in the constitution of Brazil.

There is a concern that impacts International member countries of conventions and treaties that deal with human rights, with the scope of the precaution of reprisals under International regarding the violation of human rights in a globalized world nowadays. Currently the recognition and protection of fundamental human rights have become the modern democratic constitutions based on international human rights.

Keywords: Globalization. Human rights. Effectiveness. Internationalization;constitutions. National sovereignty. Modifications. International Tribunals.

SumÁRIo: Introdução. 1. A internacionalização dos direitos humanos no Brasil. 2. A internacionalização dos direitos humanos na Argentina. 3. Breve relato sobre a internacionalização dos direitos humanos. 4. Declaração universal dos direitos humanos. 5. Dignidade da pessoa humana. 6. Breves considerações sobre a Convenção Interamericana de Direitos Humanos. 7. A Constituição Brasileira internacionalizada pelos direitos humanos. 8. A Constituição Brasileira de 1988 prevê formas de garantias de aplicação e controle das normas constitucionais e infraconstitucionais. Conclusão. Referências 


\section{INTRODUÇão}

O objetivo deste artigo é perquerir a efetividade da internacionalização dos direitos humanos em mundo globalizado, esses direitos já existiam, embora nem sempre fossem considerados em razão dos óbices no que concerne a relativização da soberania de cada Estado, no entanto, na contemporaneidade a concretização dos direitos inerentes ao homem que tem ganhado forças paulatinamente, muitas vezes provocando modificações nas Constituições em razão do receio de represálias dos Tribunais e Organizações Internacionais, tendo como escopo as mudanças que internacionalização dos direitos humanos na América Latina, principalmente nas Constituições do Brasil e da Argentina.

Indubitavelmente com a Emenda 45, de 8 de dezembro de 2004 , uma das maiores inovações no Judiciário Brasileira do últimos tempos, trouxe várias modificações para o ordenamento jurídico brasileiro, dentre as transformações deslocamento de competências, ratificação de Tratados e Convenções Internacionais aprovados pelo Congresso Nacional conforme quórum necessário para aprovação de emendas constitucionais são equivalentes às emendas constitucionais.

O que não pode se perder de vista é porque a necessidade de alterações do ordenamento externo para o ordenamento interno?

A justificativa plausível é o impacto causado com a globalização e a internacionalização de direitos humanos.

A interligação e interação globalizada seria causa da efetivação da internacionalização dos direitos humanos nos Estados, principalmente Brasil e Argentina?

Existe a prevenção de represálias no âmbito Internacional com relação a violação dos direitos humanos que enseja a relativização da soberania nacional e conseqüentemente a mudança no ordenamento positivado como forma de internacionalização dos direitos fundamentais em um mundo globalizado.

O receio de represálias internacionais fez com que no Brasil, Argentina e os países globalizados adotassem medidas de repressão a violação dos direitos humanos por precauções a responsabilização dos Estados perante Órgãos e Tribunais Internacionais.

\section{A internacionalizaÇão dos direitos humanos no Brasil}

Considerando um contexto negativo com início nos anos 1990, de barbáries e impunidades, marcados por frequentes violações aos direitos humanos, - podemos citar os casos do julgamento da missionária Dorothy Stang e advogado Manoel Mattos militantes do direitos humanos, massacres, chacinas e crimes de mando ocorridos em Eldorado dos Carajás, Vigário Geral, Carandiru, Parauapebas, Xapuri, Candelária e Queimados e entre outros.

$\mathrm{Na}$ tentativa de repelir a perpetração de impunidades e erros futuros, com 
interferência também de pressões internacionais frente ao desrespeito com os direitos fundamentais com receio de possíveis represálias internacionais.

Houve um divisor de águas jurídico com a Emenda 45 de 8 de dezembro de 2004 , uma das maiores inovações no Judiciário Brasileira do últimos tempos, trouxe dentre as transformações deslocamento de competências da justiça estadual para federal.

E ainda, a equivalência de emenda constitucional aos tratados ou convenções que versassem sobre direitos humanos quando aprovados por quórum especial de emenda constitucional, mais da metade das Assembléias Legislativas das Unidades da Federação, manifestando-se, cada uma delas, pela maioria relativa de seus membros tudo isto conforme processo legislativo indicado no art.60 da Constituição Brasileira de 1988.

Considerando o que foi dito por Picorreli, 2009 “A idéia da federalização dos crimes contra os direitos humanos, isto é, de incluir na competência da Justiça Federal o processo e julgamento de condutas violadoras de direitos humanos mantidas impunes no âmbito das agências penais dos estados-membros, começa a se desenvolver no início dos anos 90. A primeira expressão dessa idéia é encontrada no anteprojeto de lei de reformulação do Conselho de Defesa dos Direitos da Pessoa Humana (CDDPH), elaborado por uma Comissão Especial constituída pelo então Ministro da Justiça, Célio Borja(...). .A idéia surgiu em decorrência da cobrança feita por organismos internacionais ao Brasil para fazer cessar a impunidade de crimes praticados no campo e na cidade."

PIOVESAN, explica, que a internacionalização dos direitos humanos constitui, assim, um movimento extremamente recente na história, que surgiu a partir do pós guerra, como resposta às atrocidades e aos horrores cometidos durante o regime nazista, juntamente com a falta de controle estatal em garantir a eficácia desses direitos, e resguardar a dignidade humana.

Indubitavelmente, a efetividade dos direitos humanos no internacional será cada vez mais cobrada, vez que já houve várias barbáries na história como as guerras mundiais, o nazismo e entre outros, o mundo globalizado não pode coadunar com essas violações, o contrário dessas afirmações é o retrocesso de humanização, que infelizmente ainda não alcançaram os países do oriente médio, regimes totalitários e socialistas.

\section{A internacionalizaÇÃo dos direitos humanos na Argentina}

$\mathrm{Na}$ Argentina, pela última reforma, os tratados sobre direitos humanos passaram a ter força constitucional, obviamente por influência da força dos direitos humanos no plano internacional a constituição da Argentina é de 1994 e inicia-se com preâmbulo que dá conta de objetivo de se constituir união nacional, realizar-se a justiça, consolidar a paz interior, prover a defesa comum, promover-se o bem-estar 
geral e assegurar-se a todos os benefícios da liberdade, invocando-se a Deus como fonte de toda razão e justiça. Adota-se o modo representativo republicano e federal como forma de governo.

Os objetivos da reforma foram incluídos no Pacto de Olivos. Entre eles estava encurtar o mandato presidencial, mas permitir a reeleição para um único período, mitigar o presidencialismo, os direitos humanos incluem terceira e quarta geração, estabelecer penalidades contra golpes, e dar prioridade legal aos tratados internacionais, a criação de Conselho da Magistratura, a autonomia da Cidade de Buenos Aires, entre outras medidas.

Segundo Norberto Bobbio, que em sua obra -A Era dos Direitos, expressa que o grave problema da atualidade em relação aos direitos do homem, não é tanto o de justificá-los, mas o de protegê-los. Tratando-se de um problema não filosófico, mas de âmbito político.

Nos textos da Constituições do Estados Democráticos de Direito protegese os direitos humanos na tentativa de efetivá-los e evitar se represálias no plano internacional.

Como ressalta CANOTILHO, os "direitos do homem são direitos válidos para todos os povos e em todos os tempos (dimensão jusnaturalista-universalista), ou seja, os direitos do homem arrancariam da própria natureza humana e daí o seu caráter inviolável, intemporal e universal".

\section{BREVE RELATO SOBRE A INTERNACIONALIZAÇÃo DOS DIREITOS HUMANOS}

Como bem assevera AZKOUL, o processo de internacionalização dos direitos humanos pressupôs um redimensionamento acerca dos limites do conceito de soberania estatal, bem como a uma redefinição da situação do indivíduo no panorama internacional para se aduzir o status de um verdadeiro sujeito de direito internacional.

As guerras mundiais e o Nazismo significaram a ofensa de preceitos perante os direitos humanos, a internacionalização dos direitos humanos exprime esta reconstrução. $\mathrm{O}$ que demonstrou a tamanha necessidade de uma ação que ensejasse impactos na esfera internacional, o que evidentemente tornaria mais eficiente para a proteção dos direitos humanos, tendo como resultado a criação sistemática normativa de proteção internacional.

Vale salientar se que pressupõe se a relativização da soberania, antes considerada como absoluta dos Estados frente aos direitos humanos. Passando a ser uma importante efetivação na busca da reconstrução de um novo paradigma, diante do repúdio internacional às atrocidades cometidas durante a história. 


\section{DeclaraÇão universal dos direitos humanos}

É de forma universal que a DUDH certifica seus direitos, no sentido de que os receptores dos preceitos nela compreendidos não são mais para os cidadãos deste ou daquele lugar específico, mas sim todos os indivíduos sem qualquer distinção de raça, cor, sexo, língua, religião, opinião política ou de outra natureza, origem nacional ou social, riqueza, nascimento, ou qualquer outra condição.

Ainda neste âmbito, corroboramos com a lição de DALMO DALLARI, ao consagrar que a DUDH possui três objetivos fundamentais: - a certeza dos direitos, que haja uma fixação prévia e clara dos direitos e deveres, para que os indivíduos possam gozar dos direitos ou sofrer imposições; a segurança dos direitos, impondo uma série de normas tendentes a garantir que, em qualquer circunstância, os direitos fundamentais serão respeitados; a possibilidade dos direitos, exigindo que se procure assegurar a todos os indivíduos os meios necessários à fruição dos direitos, não se permanecendo no formalismo cínico e mentiroso da afirmação de igualdade de direitos onde grande parte do povo vive em condições subumanas.

\section{Dignidade da pessoa humana}

Nas palavras de SALET, os direitos humanos ou direitos do homem são, modernamente, entendidos aqueles direitos fundamentais que o homem possui pelo fato de ser homem, por sua própria natureza humana, pela dignidade que a ela é inerente. São direitos que não resultam de uma concessão da sociedade política. Pelo contrário, são direitos que a sociedade política tem o dever de consagrar e garantir.

Este conceito não é absolutamente unânime nas diversas culturas. Contudo, no seu núcleo central, a idéia alcança uma universalidade no mundo contemporâneo, como teremos ocasião de demonstrar.

Os direitos humanos são os direitos e liberdades básicos de todos os seres humanos. Normalmente o conceito de direitos humanos tem a ideia também de liberdade de pensamento e de expressão, e a igualdade perante a lei entre homens e mulheres.

Estes fundamentos mínimos considerados como necessários para a garantia da dignidade humana necessitam de tutela para a subsistência da raça humana em harmonia o que justifica a universalização dos direitos humanos entre os Estados.

Breves considerações sobre a Convenção Americana de Direitos Humanos.

Piovesan, 2006, o instrumento de maior importância no sistema interamericano é a Convenção Americana de Direitos Humanos, também denominado de Pacto de San Rose da Costa Rica, assinada em 1969, entrando em vigor em 1978. Apenas Estados Membros da Organização dos Estados Americanos têm o direito de aderir a Convenção Americana. 
No que concerne ao conteúdo, a Convenção Americana reconhece e assegura um catálogo de direitos civis e políticos similar ao previsto pelo pacto internacional dos Diretos Civis e Políticos, dentre o universo de direitos destaca-se: o direito à personalidade jurídica, o direito à vida, o direito a não ser submetido à escravidão, o direito à liberdade, o direito a um julgamento justo, o direito à compensação em caso de erro judiciário, direito à privacidade, o direito à liberdade de consciência e de religião, o direito à liberdade de pensamento e expressão, o direito à resposta, o direito à liberdade de associação, o direito ao nome, o direito à nacionalidade,o direito à liberdade de movimento e residência, o direito de participar do governo, o direito à igualdade perante à lei e o direito à proteção judicial.

È imprescindível mencionar que Convenção Americana não enuncia de forma específica qualquer direito social, cultural ou econômico; limita-se a determinar que os Estados que alcancem progressivamente.

\section{Breves considerações sobre a Convenção Interamericana de Direitos Humanos}

A comissão Interamericana de Direitos Humanos alcança todos os Estados Partes, em relação aos direitos consagrados na Declaração Americana de 1948.

Quanto à sua composição, a Comissão é integrada por sete membros " de alta autoridade moral e reconhecido saber em matéria de direitos humanos", que podem ser nacionais de qualquer Estado- membro dos Estados Americanos, seus membros são eleitos, a título pessoal, pela Assembléia Geral por um período de quatro anos, podendo ser reeleitos por mais uma vez.

A comissão tem as seguintes funções: conciliadora, assessora, crítica, legitimadora, promotora, protetora, que possui procedimento próprio para apuração se houve ou não violação da Convenção Americana por alguns do Estados-membros.

\section{A CONSTITUIÇão Brasileira INTERNACIONALIZAda PELOS DIREITOS HUMANOS}

A primeira Constituição, diz Manoel Gonçalves Ferreira Filho, a adotar, em seu texto, essa inspiração foi da de 1934, no que foi seguida pelas posteriores. As anteriores - 1824 e 1891 - como era de se esperar, manifestavam em seu texto o apego à concepção individualista dos direitos fundamentais.

Por sua vez, a Declaração contida na Constituição Brasileira de 1988 é a mais abrangente de todas as anteriores e, além de consagrar os "direitos e deveres individuais e coletivos", a Declaração de 1988 abre um capítulo para definir os direitos sociais.

Assim, a exemplo das anteriores, a Constituição da República Federativa do Brasil não pretende enumerar os direitos fundamentais; pois, além dos direitos explicitamente reconhecidos admite existirem outros decorrentes do regime e dos princípios por ela adotados. 
Portanto, hodiernamente a Constituição reconhece e assegura Direitos Fundamentais explicitamente no art. $5^{\circ}$ : Direitos cujo objeto imediato é a liberdade: de locomoção; de pensamento; de reunião; de associação; de profissão; de ação; liberdade sindical; direito de greve.

Direitos cujo objeto imediato é a segurança: dos direitos subjetivos em geral; em matéria penal (presunção de inocência); do domicílio; Direitos cujo objeto imediato é a propriedade: propriedade em geral; artística, literária e científica; hereditária.

\section{A Constituição Brasileira de 1988 prevê formas de garantias de APLI- CAÇÃO E CONTROLE DAS NORMAS CONSTITUCIONAIS E INFRACONSTITUCIONAIS}

Segundo Silva, 2003 “o Brasil seguiu o sistema norte- americano, evoluindo para um sistema misto e peculiar que combina o critério de controle difuso por via de defesa e controle concentrado por via de ação direta de inconstitucionalidade".

A forma de impedir que norma contrária à constituição permaneça no ordenamento jurídico. Cuida da eficácia dos preceitos constitucionais, tendo como base a supremacia da Constituição escrita, uma Lei maior que sobrepões as demais normas do ordenamento jurídico. As normas infraconstitucionais têm que estar em perfeita sintonia com a Lei Fundamental.

Segundo Silva, 2003 “o Brasil seguiu o sistema norte- americano, evoluindo para um sistema misto e peculiar que combina o critério de controle difuso por via de defesa e controle concentrado por via de ação direta de inconstitucionalidade".

Tendo estabelecido critérios de Controle - a) difuso - o controle da constitucionalidade é exercido por todos os órgãos integrantes do Poder Judiciário; b) concentrado - o controle é exercido por um tribunal superior do país ou por uma corte constitucional. Meio de controle - a) incidental ou via de defesa - decide sobre um fato concreto declarando-o contrário aos preceitos constitucionais, neste caso, o juiz soluciona apenas o litígio posto à sua apreciação; b) principal ou via de ação por meio de uma ação própria busca a declaração de inconstitucionalidade da norma infraconstitucional;

Natureza da decisão - a) inter partes - produz efeitos somente em relação às partes. É uma conseqüência do controle incidental; b) erga omnes - decisão produz efeitos para todos. Verifica-se no controle pela via da ação. Forma de verificar a constitucionalidade - a) abstrato ou direto - é o processo de natureza objetiva, em que é questionada a própria constitucionalidade ou não da lei, não se admitindo a discussão de situações de interesses meramente individuais; b) concreto ou indireto - é a satisfação de um direito individual.

Cláusula de reserva de plenário - Prevista no artigo 92 e artigos 480 a 482 
do Código de Processo Civil - No controle incidental, os tribunais somente podem declarar a inconstitucionalidade de lei ou ato normativo pelo voto da maioria absoluta de seus membros ou dos membros do órgão especial (depende da estrutura do tribunal).

Suspensão de Lei pelo Controle difuso - o STF após declarar inconstitucional determinada norma, no todo ou em parte, pelo controle difuso, comunica ao Senado Federal, para que ele, por meio de resolução, suspenda a vigência da norma ou dispositivo julgado inconstitucional. Lembre-se que no Brasil - O Supremo Tribunal Federal (STF) é o guardião da Constituição. Ele é a Corte Constitucional do país. As modalidades de ação direta (ADIN, ADECON, ADPF).

PIOVESAN, 2006 a sistemática internacional de proteção, bem como as obrigações internacionais, institui mecanismos de responsabilização e controle internacional, acionáveis o Estado se amostra falho ou omisso na tarefa de implementar direitos e liberdades fundamentais. Diz ainda que essas transformações decorrentes do movimento de internacionalização dos direitos humanos contribuíram ainda para o processo de democratização do próprio cenário internacional, já que além de Estado, novos sujeitos de direito passam a participar da arena internacional,como os indivíduos e as organizações não governamentais.

Sendo assim, com a cooperação dos Estados na Fiscalização da normas de direitos fundamentais formam um círculo de proteção aos direitos inerentes ao ser humano, considerando que quanto mais Estados aderirem esta forma de primazia dos direitos humanos, mais forte será o círculo de proteção da humanidade.

\section{CONClusão}

A globalização tem gerado vários impactos no que tange a efetividade da internacionalização dos direitos humanos, esses direitos já existiam, embora nem sempre fossem considerados em razão dos óbices no que concerne a relativização da soberania de cada Estado, que anteriormente era absoluta, no entanto, na contemporaneidade a concretização dos direitos inerentes ao homem tem evoluído paulatinamente, muitas vezes provocando modificações nas Constituições em razão do receio de ter que arcar com responsabilização perante os Tribunais e Organizações Internacionais.

A Constituição Federal de 1988 tem como fundamento maior a dignidade da pessoa humana conforme artigo $1^{\circ}$ inciso III da Constituição, a súmula vinculante 11 do STF, neste contexto torna- se imprescindível que seja parte de nosso ordenamento os tratados e convenções que versem sobre direitos humanos, quando aprovados por quórum especial de emenda constitucional, mais da metade das Assembléias Legislativas das Unidades da Federação, manifestando-se , cada uma de- 
las, pela maioria relativa de seus Membros tudo isto conforme processo legislativo indicado no art.60 da Constituição Brasileira de 1988

Urge salientar ainda que Emenda Constitucional 45/2004, trouxe várias alterações ao ordenamento, isto porque hoje temos a federalização dos crimes contra os direitos humanos, isto é, de incluir na competência da Justiça Federal o processo e julgamento de condutas violadoras de direitos humanos mantidas impunes no âmbito das agências penais dos estados-membros.

Existe a prevenção de represálias no âmbito Internacional com relação a violação dos direitos humanos que enseja a relativização da soberania nacional e conseqüentemente a mudança no ordenamento positivado como forma de internacionalização dos direitos fundamentais em um mundo globalizado na contemporaneidade.

Atualmente o reconhecimento e a proteção dos direitos fundamentais do homem encontram-se na base das Constituições modernas democráticas.

Observa-se ainda que os direitos fundamentais do homem constituem uma variável ao longo da história dos últimos séculos, cujo elenco se modificou e continua se modificando, ao sabor das condições históricas, dos interesses, das classes no poder ou dos meios disponíveis para a realização dos mesmos.

A internacionalização dos direitos humanos é uma ação afirmativa, vez que é uma proteção dos indivíduos contra o Estado, o que reafirma a importância do homem na sua individualidade para um mundo globalizado.

\section{REFERÊNCIAS}

ARAS, Vladimir. Federalização dos crimes contra os direitos humanos. Disponível em: http://jus.com.br/revista/texto/6762/federalizacao-dos-crimes-contra-os-direitos-humanos. Acessado em: 07.09.2013

AZKOUL, Marco Antonio. Justiça Itinerante. São Paulo: Editora Juarez de Oliveira, 2006. p. 22.

BOBBIO, Norberto. A era dos direitos. Rio de Janeiro: Campus, 1997-2004. p. 217.

CANOTILHO, J. J. Gomes. Direito Constitucional e Teoria da Constituição. 7. ed. Coimbra: Almedina, 2003. p. 39.

FERRAZ, Anna Candida da Cunha. Constituição federal interpretada artigo por artigo e parágrafo por parágrafo.Costa Machado Organizador. pp.5-51

MEDINA, Paulo Roberto de Gouvêa. Direito Processual Constitucional. Rio de janeiro, 2006- Editora Forense.

PICORELLI, Fernanda Estevão. O Incidente de Deslocamento de Competência como mais um mecanismo de proteção dos direitos humanos. Jus Navigandi, Teresina,ano14,n.2195,5jul.2009,Disponívelem: http://jus.com.br/revista/texto/13102. 
Acessado em:07.09.2013.

PIOVESAN, Flávia. Direitos Humanos e o Direito Constitucional Internacional, 7. ed., revista, ampliada e atualizada.

SILVA, José Afonso da. Curso de Direito Constitucional Positivo, 23. ed. revista e atualizada, 2003.

Streck, Lênio Luiz. Hermenêutica Jurídica e (m) crise: uma exploração hermenêutica da construção do direito. 5. ed.,1999 revista e atualizada.

SARLET, Ingo Wolfgang. A Eficácia dos Direitos Fundamentais. 7. ed.,Porto Alegre, Livraria do Advogado, 2007.

Dignidade da Pessoa Humana e Direitos Fundamentais na Constituição Federal de 1988. 5. ed., Porto Alegre, Livraria do Advogado, 2007.

www.jus .com.br, pesquisa realizada em 10.09.13.

http://es.wikipedia.org/wiki/Reforma_constitucional_argentina_de_1994, pesquisa realizada em 10.09.13. 